\title{
Composite index of anthropometric failure and geographic altitude in children from Jujuy ( 1 to 5 years old)
}

Ignacio Felipe Bejarano, B.S. ${ }^{a}$, Ángel Rafael Carrillo, Technician in Anthropometry ${ }^{a}$,
José Edgardo Dipierri, M.D. ${ }^{b}$, Estela María Román, B.S. ${ }^{b}$ and Guadalupe Abdo, B.S. ${ }^{a}$

ABSTRACT

Introduction. The Composite Index of Anthropometric Failure (CIAF) is made up of typical anthropometric indicators and their combination into seven categories, and proposes an additional measure to study malnutrition as an alternative to the evaluation of stunting, wasting and underweight as separate measures. Objective. To assess the CIAF in the child population settled at different altitudinal zones in Jujuy.

Population and Methods. Weight and height were obtained from healthy 1 to 5 yearold control children, measured at primary healthcare centers (PHCCs) in Jujuy between 2005 and 2007. Nutritional status indicators such as underweight, stunting and wasting were determined as per the World Health Organization 2007 child growth standards. The CIAF and its seven categories were estimated by grouping data by gender, age and altitudinal zone (highlands: $\geq 2500$ MASL; lowlands: $<2500$ MASL). The CIAF percentage differences for height, gender and age were verified using a chi-square test.

Results. A total of 8059 children were included. The CIAF for highland children $(6.1 \%)$ doubled that for lowland children $(3.4 \%)(p<0.05)$, and underweight prevalence (group $\mathrm{Y}$ ) was significantly higher in the highlands $(p<0.05)$. The CIAF value and stunting (group F) increased with age, but such increase was more significant in the highlands.

Conclusions. A significantly higher CIAF was observed in highland children, at the expense of stunting. However, the index of anthropometric failure was not more than $10 \%$ at both the highlands and the lowlands, and this accounts for a scarcely significant malnutrition health status in the studied child population of Jujuy. Key words: geographic altitude, index of anthropometric failure, child population, Jujuy, growth.

http:/ /dx.doi.org/10.5546/aap.2014.eng.526

\section{INTRODUCTION}

Conventional malnutrition indicators evidence different growth biological processes by default, but they overlap one another and none is useful per se to provide an objective estimate of the number of malnourished children. ${ }^{1}$
Underweight (<-2 Wz weight/age) combines the effects of two different dimensions of child growth: increase of height with age and fluctuation of body proportions. For this reason, underweight may be caused by stunting or insufficient weight gain for height, or a combination of both. Stunting ( $<-2 \mathrm{Wz}$ height/age) reflects skeletal growth retardation due to chronic malnutrition and other factors (health problems, decreased partial pressure of oxygen in high altitude regions, etc.), i.e. a chronic process, and wasting ( $<-2 \mathrm{Wz}$ weight/height) is a measure of malnutrition that reflects loss of fat and lean tissue., ${ }^{2,3}$

In 2000, Svedberg ${ }^{4}$ proposed an alternative means to present data on child malnutrition at a population level, the composite index of anthropometric failure (CIAF), which got its name because it combines data related to underweight, stunting and wasting. Svedberg based his proposal on the following: 1) underweight, stunting and wasting are not independent indicators; 2) underweight, which is usually used to evaluate chronic and acute malnutrition, is not useful to distinguish between stunting and wasting; 3 ) underweight may underestimate the effect of anthropometric failure in the population because it is not able to identify the number of stunted and/ or wasted children. The CIAF would provide a single population measure that comprises underweight, stunting and wasting, and synthesizes the percentage of malnourished children.

According to different data, it has been established that geographic high altitude and its associated adverse 
factors have a negative impact on growth across the different ontogenesis stages, and such influence is evidenced in a lower birth weight, and body mass index and shorter height in populations living above 2500 MASL compared to others living closer to sea level. ${ }^{5-11}$

The objective of this study was to evaluate and compare the CIAF in the child population of different altitudinal zones in Jujuy.

\section{POPULATION AND METHODS}

It is a descriptive, retrospective and observational study based on a convenience sample. Anthropometric data were obtained from healthy child controls studied between 2005 and 2007 at primary healthcare centers (PHCCs), which are part of the Program of Primary Health Care of the Ministry of Health and Social Welfare in the province of Jujuy. The PHCCs are distributed across the five healthcare regions (Puna, Quebrada, Valles, Ramal 1 and Ramal 2), which comprise 22 programmatic areas and 296 PHCCs. Data were randomized using an Excel spreadsheet, and only one control was taken from each child who had anthropometric data for weight, height, age and date of measurement, regardless of their health status.

Despite the demographic and socio-economic differences present in the province of Jujuy in relation to geographic altitude, ${ }^{12}$ individuals and families seen at the PHCCs usually have no social insurance and live in socioeconomically disadvantaged neighborhoods and towns. In addition,most of these children and their families participate in different national food and social assistance programs (Mother and Child Program, Universal Child Allowance), which warrant a relative cultural and socioeconomic homogeneity in the child population of this study. The sample represents approximately $18 \%$ of the overall population of Jujuy in the analyzed age group. ${ }^{13}$

Height and weight data used corresponded to boys and girls aged 1 to 5 years old (decimal age: $1.0-5.99) \cdot{ }^{14}$ International ${ }^{15}$ and national ${ }^{16}$ recommendations were followed when the PHCC staff, specifically trained for this task, took anthropometric measures. Up to 2 years old, weight $(\mathrm{kg})$ was measured using beam scales with divisions that read up to $50 \mathrm{~g}$, while length was measured with the child in supine position using an infantometer, which has a sturdy horizontal surface with a measuring tape across it and a mobile vertical surface that slides at a right angle over the horizontal surface ${ }^{17}$ For children older than 2 years old, height was measured with an altimeter with $0.5 \mathrm{~cm}$ variations.

Nutritional status was characterized based on the World Health Organization child growth standard, ${ }^{18,19}$ using underweight, stunting and wasting indicators.

The percentage of children in each of the seven CIAF categories was estimated (Table 1). Originally, the model proposed by Svedberg 20 included six nutritional status groups: A) without anthropometric failure, including children with weight and height adequate for their age; B) wasted only; C) wasted and underweight; D) stunted, underweight and wasted; E) stunted and underweight; F) stunted only. Afterwards, Nandy, et al. ${ }^{21}$ added group Y (underweight only). The CIAF excludes group A and it is estimated by adding the remaining groups ( $\mathrm{B}$ through $\mathrm{Y}$ ), i.e., it includes all children with underweight, stunting or wasting, or a combination thereof (Table 1).

TABLE 1. Anthropometric failure groups (modified as per Svedberg's model, 2000)

\begin{tabular}{|c|c|c|c|c|}
\hline Group & Description & Wasted & Stunted & Underweight \\
\hline A & $\begin{array}{l}\text { Without failure: children whose height and weight are above } \\
\text { the specific standard for their age and who have no anthropometric deficit. }\end{array}$ & No & No & No \\
\hline B & $\begin{array}{l}\text { Wasted: children with acceptable weight and height for their age, } \\
\text { but whose weight is lower than the standard for their height. }\end{array}$ & Yes & No & No \\
\hline $\mathrm{C}$ & $\begin{array}{l}\text { Wasted and underweight: children with normal height, but with low weight } \\
\text { for their age and low weight for their height. }\end{array}$ & Yes & No & Yes \\
\hline $\mathbf{D}$ & $\begin{array}{l}\text { Wasted, stunted and underweight: children with anthropometric failure in } \\
\text { the three measurements. }\end{array}$ & Yes & Yes & Yes \\
\hline $\mathrm{E}$ & $\begin{array}{l}\text { Stunted and underweight: children with low weight and height for their age, } \\
\text { whose weight for their height is acceptable. }\end{array}$ & No & Yes & Yes \\
\hline $\mathbf{F}$ & $\begin{array}{l}\text { Stunted: children with low height for their age, with acceptable weight } \\
\text { for their short stature. }\end{array}$ & No & Yes & No \\
\hline $\mathbf{Y}$ & Underweight: children with low weight for their age. & No & No & Yes \\
\hline
\end{tabular}


The difference between the total CIAF value and group Y (underweight only) was estimated and used as an indicator of cases of malnutrition that are not reflected when underweight is exclusively assessed.

For analysis, data were grouped by gender, years in decimal age, and PHCC geographic location. Decimal age was estimated considering the date of measurement and the date of birth, and four age groups were established: 1-1.99 years old, 2-2.99 years old, 3-3.99 years old and 4-4.99 years old. Based on PHCC geographic location, data were grouped into two altitudinal zones: 1 ) highlands (HL) ( $\geq 2500$ MASL) and 2$)$ lowlands (LL) (<2500 MASL).

The CIAF differences for height, gender and age were verified using a chi-square test.

\section{RESULTS}

A total of 8059 children were included (3967 boys and 4092 girls).

Table 2 shows that, regardless of gender and geographic altitude, 1) no children was included in category B (wasted), C (wasted and underweight) and D (stunted, underweight and wasted); 2) the most common category was A (normal weight and height), which reached more than $90 \%$.

For category $\mathrm{F}$ (stunting), the value observed in the HL was twice the one observed in the LL, which is also the case of the CIAF (Table 2).

In terms of age groups, regardless of geographic altitude, category $\mathrm{F}$, the CIAF and the Y-CIAF difference increased with age, although such increase was significantly higher in the HL (Table 3).

\section{DISCUSSION}

It should be pointed out that this is the first study conducted in relation to using the CIAF to assess the nutritional status of an Argentine population. Most of the data about the use of the CIAF come from countries with high child mortality rates (India, Bangladesh, Nepal, Nigeria, Libya and Ghana). 1,2,20,21 In Latin America, the CIAF has been used only in three countries: Peru, Bolivia and the Dominican Republic.,22

Differences among countries may be related to socio-economic inequalities evidenced in child mortality rates estimated for 2014: Bolivia (38.6/1000), Peru (20.2/1000), Dominican Republic (19.6/1000), Argentina (9.9/1000).

Although the HL and LL prevalences in relation to the CIAF are significantly different, they are much lower than the prevalences observed in the Dominican Republic (12.5\%), Peru $(23.8 \%)$ and Bolivia (26.6\%). ${ }^{2,22}$ Such difference is higher when compared to values reported in India, which are over $50 \%$ across the country, or even as high as $70 \%$ in some regions, such as West Bengal. ${ }^{1,2}$

Growth restriction as the result of a socially or ecologically adverse environment, inadequate diet and nutrition, and various infections (viral, bacterial or parasitic) becomes evident by underweight, wasting and stunting as anthropometric indicators. In Latin America and the Caribbean, out of all deaths occurred in

TABLE 2. Number of individuals (\%) and statistically significant difference by category included in the composite index of anthropometric failure by gender and geographic altitude

\begin{tabular}{|c|c|c|c|c|c|c|}
\hline \multirow{2}{*}{$\begin{array}{l}\text { Gender } \\
\text { Categories }\end{array}$} & \multicolumn{2}{|c|}{ Male } & \multicolumn{2}{|c|}{ Female } & \multicolumn{2}{|c|}{ Total } \\
\hline & HL & LL & HL & LL & HL & LL \\
\hline Total & $2050(100)$ & 1938 (100) & $2189(100)$ & 1917 (100) & $4239(100)$ & 3855 (100) \\
\hline A & $1926(93.9)^{*}$ & $1875(96.7)^{*}$ & $2053(93.8)^{*}$ & $1850(96.5)^{*}$ & $3979(93.9)^{*}$ & $3725(96.6)^{*}$ \\
\hline B & 0 & 0 & 0 & 0 & 0 & 0 \\
\hline $\mathrm{C}$ & 0 & 0 & 0 & 0 & 0 & 0 \\
\hline $\mathrm{D}$ & 0 & 0 & 0 & 0 & 0 & 0 \\
\hline $\mathrm{E}$ & 0 & $1(0.05)$ & $6(0.3)^{*}$ & $1(0.05)^{*}$ & $6(0.1)^{*}$ & $2(0.1)^{*}$ \\
\hline $\mathrm{F}$ & $124(6.1)^{*}$ & $60(3.1)^{*}$ & $125(5.7)^{*}$ & $59(3.1)^{*}$ & $249(5.9)^{*}$ & $119(3.1)^{*}$ \\
\hline $\mathrm{Y}$ & 0 & $2(0.15)$ & $5(0.2)^{*}$ & $7(0.35)^{*}$ & $5(0.1)^{*}$ & $9(0.2)^{*}$ \\
\hline CIAF (B through Y) & $124(6.1)^{*}$ & $63(3.2)^{*}$ & $136(6.2)^{*}$ & $67(3.4)^{*}$ & $260(6.1)^{*}$ & $130(3.4)^{*}$ \\
\hline Y-CIAF & 6.1 & 3.1 & 6 & 3.1 & 6 & 3.2 \\
\hline
\end{tabular}

* Statistically significant differences $(\mathrm{p}<0.05)$.

HL: highlands.

LL: lowlands.

CIAF: composite index of anthropometric failure. 
2011 in children younger than 5 years old due to infectious causes (diarrhea, pneumonia, measles, and other infections) $25 \%$ were associated with underweight, $65 \%$ with stunting, and $10 \%$, with wasting. ${ }^{23}$

The individual estimate, separate from this anthropometric deficit, overlooks the fact that multiple deficits may occur simultaneously. The CIAF would allow to improve such underestimation of the mortality risk attributed to the combined and synergistic action of these anthropometric indicators of malnutrition and poverty. However, out of the CIAF groups that combine more than one indicator (C, D and $\mathrm{E})$, only group $\mathrm{E}$ was observed in the population of Jujuy, and its percentage was negligible (Tables 2 and 3 ).

The difference between the CIAF and group $Y$ (underweight) allows to assess underestimation, which is over $90 \%$ regardless of geographic altitude, only if this last indicator is used in the child population of Jujuy (Table 2). According to Nandy and Miranda, ${ }^{22}$ such difference clearly shows that underweight as an indicator misses a variable number of malnourished children. Additionally, this difference allows to objectively estimate the advantage of the CIAF over conventional indicators used individually when assessing the severity of overall malnutrition of a given population (Table 2).

In 2011, the prevalence and 95\% confidence intervals (CIs) for stunting and underweight in South American children younger than 5 years old were $11.5 \%(6.9-18.6)$ and $3.1 \%(2.0-4.8)$, respectively. ${ }^{23}$
Prevalences observed in Jujuy for these two indicators are below the proposed CIs and reveal that the pediatric population of Jujuy has an acceptable nutritional status, even those who live above 2500 MASL (Table 2). The CIAF results also point in this direction since the percentage observed in the LL usually corresponds to that expected for a normal distribution. At present, there are no cut- off points nor scales to assess the effect of the CIAF, except for an inter-population comparison and its value as a predictor of morbidity or mortality. Mortality risk associated with multiple anthropometric deficits worsens as these increase. Based on a recent meta-analysis using individual data from prospective studies carried out in 10 developing countries, including Peru, the mortality risk is 3.4 times higher in stunted and underweight children (group E), 4.7 times higher in wasted and underweight children (group C) and 12.3 times higher in stunted, wasted and underweight children (group D) compared with children with no deficits (group A). ${ }^{24}$

In the population of Jujuy, the percentage of stunted and underweight children is slightly higher in the HL, and this is consistent with the higher child mortality rates observed in these populations. ${ }^{6}$

The category that contributes the most to the CIAF in the population of Jujuy is group F (stunted), and this is significantly higher in the HL. In general, stunting is attributed to chronic malnutrition. However, in populations of Jujuy, it may also be the result of hypoxia and the synergistic action of hypoxia with other factors

TABLE 3. Number of individuals (\%) by category included in the composite index of anthropometric failure by age and geographic altitude

\begin{tabular}{|c|c|c|c|c|c|c|c|c|}
\hline \multirow{2}{*}{$\frac{\text { Altitude }}{\text { Age }}$} & \multicolumn{4}{|c|}{ HL } & \multicolumn{4}{|c|}{ LL } \\
\hline & $1.0-1.9$ & $2.0-2.9$ & $3.0-3.9$ & $4.0-4.9$ & $1.0-1.9$ & $2.0-2.9$ & $3.0-3.9$ & $4.0-4.9$ \\
\hline $\mathrm{A}$ & 1279 (97.5) & 1103 (94.7) & 944 (93.3) & $653(87.1)$ & $1153(98.8)$ & $1003(96.6)$ & 847 (96.0) & $722(94.0)$ \\
\hline B & 0 & 0 & 0 & 0 & 0 & 0 & 0 & 0 \\
\hline C & 0 & 0 & 0 & 0 & 0 & 0 & 0 & 0 \\
\hline $\mathrm{D}$ & 0 & 0 & 0 & 0 & 0 & 0 & 0 & 0 \\
\hline $\mathrm{E}$ & $1(0.1)$ & $5(0.4)$ & 0 & 0 & $1(0.1)$ & $1(0.1)$ & 0 & 0 \\
\hline $\mathrm{F}$ & $29(2.2)$ & $55(4.7)$ & $68(6.7)$ & $97(12.9)$ & $9(0.8)$ & $29(2.8)$ & $35(4.0)$ & $46(6.0)$ \\
\hline Y & $3(0.2)$ & $2(0.2)$ & 0 & 0 & $4(0.3)$ & $5(0.5)$ & 0 & 0 \\
\hline \multicolumn{2}{|c|}{$\begin{array}{l}\text { CIAF } \\
(\text { B through Y) } 33 \text { (2.5) }\end{array}$} & $62(5.3)$ & $68(6.7)$ & 97 (12.9) & $14(1.2)$ & $35(3.3)$ & $35(4.0)$ & $46(6.0)$ \\
\hline CIAF-Y & 2.3 & 5.1 & 6.7 & 12.9 & 0.9 & 2.8 & 4.0 & 6,0 \\
\hline
\end{tabular}

* Statistically significant differences $(\mathrm{p}<0.05)$.

HL: highlands. LL: lowlands.

CIAF: composite index of anthropometric failure. 
(nutritional and infectious). This assumption is based on the fact that the prevalence of underweight in populations of Jujuy is generally very low, even lower in the HL, and that it tends to reduce with age; no 4 or 5 year-old child was observed to be underweight in either altitudinal zone (Table 3). However, the prevalence of stunting significantly increases with age and such increase is higher in the HL, so that, at 5 years old, $12.6 \%$ of children from the HL have stunting, versus $5.6 \%$ from the LL (Table 3 ).

The CIAF categories have been questioned because the combination of indicators included in group B is anthropometrically impossible, group $C$ is of little immediate interest in the health field since these children may turn out to be thin adults, and groups D, E, F and $\mathrm{Y}$ are already covered by the Waterlow classification. ${ }^{25}$ However, the representation of the groups in question is directly related to the socio-economic conditions of studied countries or regions. For example, West Bengal has a 55.4 child mortality rate and a 78.3 mortality rate in children younger than 5 years old in 2003-2004, with $7.2 \%$ of wasted children and $10.7 \%$ of children who had all three deficits. ${ }^{1,26}$

The CIAF has also been questioned because its indicators fail to capture the emerging problem of obesity among poor individuals, which is the combination of stunting and obesity that has been observed in Latin American countries. ${ }^{2,27}$ In the province of Jujuy, such nutritional status was observed only in boys from the LL, in $8.3 \%$ of stunted children.

It is likely that the CIAF has little clinical applicability. However, despite these objections, the CIAF can provide politically relevant information about the pattern of pediatric malnutrition at a population level by summing up this condition into a single value and avoiding missing or underecording of malnourished children, which is the case of using individual indicators of stunting, wasting and underweight.

\section{CONCLUSION}

The child population from the HL had a significantly higher CIAF. However, the CIAF is low in both altitudinal zones, which reflects a scarcely significant malnutrition health status in the studied child population of Jujuy.

\section{REFERENCES}

1. Mandal GC, Bose K. Assessment of overall prevalence of undernutrition using Composite Index of Anthropometric Failure (CIAF) among preschool children of West Bengal,
India. Iran J Pediatr 2009;19(3):237-43.

2. Nandy S, Svedberg P. The Composite Index of Anthropometric Failure (CIAF): an alternative indicator for malnutrition in young children. En Preedy VR, ed. Handbook of Anthropometry: Physical Measures of Human Form in Health and Disease. New York: Springer; 2012. Págs.127-37.

3. Klaver W. Underweight or stunting as an indicator of the MDG on poverty and hunger. ASC Working Paper 92. Leiden, The Netherlands: African Studies Centre, 2010. Available at: https://openaccess.leidenuniv.nl/ handle/1887/16313. [Accessed on: December 5, 2013].

4. Svedberg P. Poverty and undernutrition: theory, measurement and policy. New York: Oxford University Press. Anthropometric indicators of undernutrition: measurements and evidence 2000;153-72.

5. Álvarez PB, Dipierri JE, Bejarano IF, Alfaro EL. Variación altitudinal del peso al nacer en la Provincia de Jujuy. Arch Argent Pediatr 2002;100(6):440-7.

6. Meyer E, Carrillo R, Román EM, Bejarano IF, et al. Prevalencia de sobrepeso y obesidad en escolares jujeños de diferente nivel altitudinal según las referencias IOTF, CDC y OMS. Arch Argent Pediatr 2013;111(6):516-22.

7. GrandiC, Dipierri J, Luchtenberg G, Moresco A, et al. Efecto de la altitud sobre el peso al nacer y eventos perinatales adversos en dos poblaciones argentinas. Rev Fac Cien Med Univ Nac Cordoba 2013;70(2):55-62.

8. Bejarano IF, Dipierri JE, Andrade A, Alfaro EL. Geographic altitude, surnames, and height variation of Jujuy (Argentina) conscripts. Am J Phys Anthropol 2009;138(2):158-63.

9. Bejarano I, Dipierri J, Alfaro E, Quispe Y, et al. Patrón de crecimiento y evaluación nutricional de la población infantil jujeña. Cuad Fac Humanid Cienc Soc, Univ Nac Jujuy 2004;22:195-210.

10. Moreno Romero S, Lomaglio DB, Jail Colome J, Alba JA, et al. Condición nutricional en la puna argentina. Observat Medioamb 2005;8:111-25.

11. DipierriJE, Bejarano IF, Alfaro E, SpioneC. Rural and urban child's height and its relation to geographic altitude in the province of Jujuy (Argentina). Acta Med Auxol (Milano) 1998;30(1):11-17.

12. Bejarano IF, Alfaro EL, Torrejón I, Pacheco JL, et al. Composición corporal y adiposidad en adultos jujeños de distintos niveles altitudinales. Rev Argent Antropol Biol 2013;15(1):29-36.

13. Instituto Nacional de Estadísticas y Censos. Censo Nacional de Población, Hogares y Vivienda. Provincia de Jujuy. Población total por sexo e índice de masculinidad, según edad en años simples y grupos quinquenales de edad. Año2010. Buenos Aires: Instituto Nacional de Estadísticas yCensos;2010. Available at: http:/ /www.censo2010.indec. gov.ar/CuadrosDefinitivos/P2-P-Jujuy.pdf. [Accessed on: June 27, 2014].

14. Bogin B. Patterns of human growth. Cambridge: Cambridge University Press, 1988. Basic principles of human growth;54-97.

15. Cole TJ. The use of growth references. En: Ulijaszek SJ, Johnston FE, Preece MA, eds. The Cambridge Encyclopedia of Human Growth and Development. Cambridge: Cambridge University Press; 1998; 80-95.

16. Sociedad Argentina de Pediatría. Comité Nacional de Crecimiento y Desarrollo. Guías para la evaluación del crecimiento físico. 2da ed. Buenos Aires: SAP; 2001. Concepto y uso de estándares de crecimiento; 33-100.

17. Sociedad Argentina de Pediatría. Comité Nacional de Crecimiento y Desarrollo. Guía para la evaluación del crecimiento físico. 3ra ed. Buenos Aires:SAP;2013. Técnicas antropométricas; 19-26. 
18. De Onis M, Blössner M. The World Health Organization Global Database on Child Growth and Malnutrition: methodology and applications. Int. J. Epidemiol 2003;32(4):518-26.

19. De Onis M, Garza C, Victora CG, Onyango AW, et al. The WHO Multicentre Growth Reference Study: planning, study design, and methodology. Food Nutr Bull 2004;25(1 Suppl):S15-26.

20. Svedberg P. How many people are malnourished? Annu Rev Nutr 2011;31:263-83.

21. Nandy S, Irving M, Gordon D, Subramanian SV, et al. Poverty, child undernutrition and morbidity: new evidence from India. Bull World Health Organ 2005;83(3):210-6.

22. Nandy S, Miranda JJ. Overlooking undernutrition? Using a composite index of anthropometric failure to assess how underweight misses and misleads the assessment of undernutrition in young children. Soc Sci Med 2008;66(9):1963-6.
23. Black RE, Allen LH, Bhutta ZA, Caulfield LE, et al. Maternal and child undernutrition: global and regional exposures and health consequences. Lancet 2008;371(9608):243-60.

24. McDonald CM, Olofin I, Flaxman S, Fawzi WW, et al. The effect of multiple anthropometric deficits on child mortality: meta-analysis of individual data in 10 prospective studies from developing countries. Am J Clin Nutr 2013;97(4):896901.

25. Bhattacharyya AK. Composite index of anthropometric failure (CIAF) classification: is it more useful? Bull World Health Organ 2006;84(4):335.

26. De P, Dhar A. Inequality in child mortality across different states of India: a comparative study. J Child Health Care 2013;17(4):397-409.

27. Fernald LC, Neufeld LM. Overweight with concurrent stunting in very young children from rural Mexico: prevalence and associated factors. Euro J Clin Nutr 2007;61(5):623-32. 